\title{
Role of Perceived Management Support and Personal Valence in Promoting Behavioral Support for Change: A Social Exchange Theory Perspective
}

\author{
Farhan Mehboob $^{1}$, Noraini Othman ${ }^{2}$ \\ ${ }^{1,2}$ School of Business Management, Universiti Utara Malaysia \\ farhan.mehboob9@gmail.com
}

\begin{tabular}{ll}
\hline ARTICLEDETAILS \\
\hline History \\
Received $\quad$ :August \\
Revised Format $:$ September \\
Accepted $\quad$ : October \\
\hline
\end{tabular}

Keywords :

Organizational Change; Perceived Management Support; Personal

Valence; Behavioral Support for

Change; Social Exchange Theory

\begin{abstract}
S
Individuals' support for change is a critical success factor to effectively implement change. Therefore, identifying the possible antecedent and mechanism leading to one's behavioural support towards change is necessary. The study aims to unfold this avenue of research empirically by examining the role of both person and context factor in promoting behavioral support for change. Data was collected from 292 academic staff of six public sector universities in Pakistan via cross-sectional mean. A selfreported questionnaire was used to collect responses from the desired sample. SPSS 25 and AMOS were used to analyse the data for its relevance to study's objectives. Results revealed a positive impact of perceived management support on academic staff's behavioural support for change. Moreover, personal-valence provides an effective intervening mechanism to translate the effect of perceived management support on both dimensions of behavioural support for change such as compliance and championing behaviour. The study contributes to the existing literature on organizational change particularly to the university settings by examining and empirically validating both person and context factor as significant predictors to academic staff's behavioral support for change.
\end{abstract}

(C2020 STIM Lasharan Jaya Makassar

\section{INTRODUCTION}

Ongoing and continuous change has substantially reshaped the nature and scope of tasks as well as organizations (Cascio \& Aguinis, 2008). Breakthrough in the areas of information and technology have challenged the survival and existence of many of the organizations across the globe (Tomprou, Nikolaou, \& Vakola, 2012). The globalization and competitive pressure; rapidly evolving choices for communities, societies and customers; and the growing complexity in social and technical ties have been identified as one of those potential factors that have been pushing organizations to continually adapt themselves to the changing dynamics (Schreyögg \& Sydow, 2010). Thereby, for organizations, to survive and flourish, they have to enhance their resilience toward these socio-economic fluctuations (Burke, 2002). Consequent upon, organizations have to take frequent initiatives to bring about change in important organizational constituents (Amis \& Aïssaoui, 2013). The nature and scope of this change could be diverse and constituted of multiphase interventions such as downsizing (Day, Armenakis, Feild, \& Norris, 2012), mergers (Kavanagh \& Ashkanasy, 2006), restructuring and strategic change (Wanberg \& Banas, 2000), to quality improvement initiatives (Coyle-Shapiro, 1999). This diversity in change make it difficult to interpret its ultimate outcomes (Stouten, Rousseau, \& De Cremer, 2018) and hence mainly rely on subjective assessment and evaluation (Hiatt, 2006).

In response to the novel ways of doing businesses and providing services through structural and process transformations; employees' response towards these change initiatives has been becoming increasingly critical in order to sustain and make change more of a successful venture (Bouckenooghe, M. Schwarz, \& Minbashian, 2015; Oreg, Bartunek, Lee, \& Do, 2018; Oreg, Vakola, \& Armenakis, 2011; van den Heuvel, Demerouti, \& Bakker, 2014). 
There is a consensus prevailing all over the change management literature and practices that employees' positive reaction and support is key to the success of organizational change (Bakari, Hunjra, \& Niazi, 2017; Shin, Taylor, \& Seo, 2012; Zhao, Seibert, Taylor, Lee, \& Lam, 2016). For instance, past studies have indicated that one of the major causes of massive failure rates of about every two-third of the change initiatives have been due to employees lack of support toward change (Cinite, Duxbury, \& Higgins, 2009; Jansson, 2013; Michel, Todnem, \& Burnes, 2013).

Given the role of individuals' support as a key success factor to bring about change, identifying ways to enact such change support related response has been positing a serious challenge. Pertaining to address the subsequent issue, current study examines the potential intervening mechanism through which the change supportive behavioral response likely to be manifested and lead organizations toward better adaptation to the change. The study in particular, aims to uncover the role of context and person factors in facilitating one's behavioral support to change. In order to understand the innate complexities of organizational change and its implications, consideration of both personal and context factor is important to capture the essence of organizational change and its effective implementation to the context. Although, past literature on organizational change has elicited both personal and context factors as fundamental to successfully bring about change (Fugate \& Soenen, 2018; Oreg et al., 2018, 2011), however, rarely have been explored yet in relation to their simultaneous examination in a same study (Fugate \& Soenen, 2018).

To assist in advancement of the suggestions, current study addresses this limitation by focusing on the corresponding factors and their underlying relationship pattern in response to the organizational change. Specifically, the study sought to examine the intervening role of personal valence (person factor) in the relationship between the perceived management support (context factor) and individuals' behavioral support for change (support factor). The study argues that perceived management support to behavioral support for change relationship would be mediated and effectively translated when the individuals found high at their valence level. In brief, perceived management support likely to induce the valence level among individuals which may lead to subsequent change-oriented support behaviors.

\section{LITERATURE REVIEW}

\section{Impact of Perceived Management Support on Behavioral Support for Change}

Prior research on organizational change opined that individuals' perception and beliefs towards change result in behaviours that are persistent, effortful and focused in their attempts to support and facilitate the effective implementation of the change initiatives (Haffar, Al-Karaghouli, Irani, Djebarni, \& Gbadamosi, 2019; Iqbal \& Asrar-ul-Haq, 2018; Oreg et al., 2018, 2011; Rafferty, Jimmieson, \& Armenakis, 2013). Taken an account of the behavioural perspective to change, Herscovitch and Meyer (2002) distinguished these behavioural manifestations in relation to their level of activation and support towards change either via passive or active orientation namely compliance and championing behaviour. According to them, the minimal acceptable level of support that can be carried out during the change is 'compliance' with the statutory instructions, rules and directions in view of the change under consideration. It is "demonstrating minimum support for a change by going along with the change, but doing so reluctantly" (p. 478). Compliance "occurs when the target person carries out the requested action but is apathetic about it rather than enthusiastic, makes only a minimal or average effort, and does not show any initiative" (Falbe \& Yukl, 1992, p. 639). Championing behaviour on the other hand, involves in "demonstrating extreme enthusiasm for a change by going above and beyond what is formally required to ensure the success of the change and promoting the change to others" (p. 478). Championing "occurs when a target person agrees internally with an action or decision, is enthusiastic about it, and is likely to exercise initiative and demonstrate unusual effort and persistence in order to carry out the request successfully" (Falbe \& Yukl, 1992, p. 640). Discretionary efforts therefore are important practical and conceptual means of distinguishing between employee compliance and championing behavior. Accordingly, identifying relative antecedent and their relationship with these forms of support behaviors is 
valuable for researchers and practitioners. The subsequent significance of behavioral support for change combined with paucity of empirical research examining the bi-folded perspectives to support behaviors provide a core impetus to conduct this study.

Referring to the importance of context factors to successfully inculcate the support for change, the study aims to examine the role of perceived management support as a potential contextual antecedent to induce a positive stimulus among individuals towards change. It has generally been viewed as an important context attribute in successful implementation of organizational change (Armenakis \& Bedeian, 1999; Neves, 2009). Perceive management support refers to the provision of support from organizational leaders, including both formal and informal leaders (Armenakis \& Fredenberger, 1997), opinion leaders or change agents (Armenakis, Bernerth, Pitts, \& Walker, 2007). Jimmieson, Terry and Callan, (2004) argued that "one of the managerial challenges facing organizations, is the effective implementation of organizational change programs that minimize feelings of uncertainty and associated threat" (p. 11). This highlights how top management is primarily responsible for influencing employee perceptions, expectations, appraisals and behavioral reactions to successfully implement change (Rafferty \& Restubog, 2017). Rafferty et al. (2013) coincides it with 'internal context enablers', which often elicits change management processes that foster individuals' vertical coordination with the higher-ups and stimulate positive work behaviors. Vakola (2014) argued that employees who perceive their managers are supportive, inspiring and trustworthy and openly communicate the change are more likely to develop a positive image regarding the change that ultimately lead employees to demonstrate their support toward change.

A review of past research reveals that perceived management support serve as central function in enacting employee acceptance to change. For instance, while examining the role of supportive leadership as a predictor to employee commitment to change, Sharma et al. (2018) found a strong positive association between each other. Likewise, Rafferty and Minbashian (2019) in a recent study observed that perceived management support significantly leads to employees' change supportive behaviors. A study by Bakari et al. (2017) also indicated perceived management support as an antecedent to one' commitment to change. In brief, when employees report that their leaders and superiors provide adequate support necessary to implement change, their perceived extent of available opportunities to engage into supportive behaviors enhance thus resulting in manifestation of more supportive behavior in relation to the corresponding organizational change. In view of the theoretical rationale and empirical evidences, the study thereby hypothesizing that perceived management support is related to both compliance and championing dimensions of individuals' support toward change.

H1a: Perceived management support is positively related to compliance behavior

H1b: Perceived management support is positively related to championing behavior

\subsection{Mediating Role of Change-valence in the Relationship between Perceived Management Support and Dimensions of Behavioral Support for Change}

There is a common belief that perceived management support will improve the motivation level of employees and has its root in social exchange theory (SET). According to Blau (1964), the social exchange theory primarily focuses on two dimensional view of relationships between employees and employers; social exchange and economic exchange. Compared to employers maintaining social exchange, employees maintain economic exchange with employer to engender strong feelings of gratitude, trust and reciprocity. In connection, employees more rely on the inducements they receive from their employers in shape of developmental rewards and benefits packages (Hom et al., 2009). More valuable the inducements are more likely they will develop a deeper obligation to their organizations over time (Rousseau, 2005).

In view of the social exchange theory, change-valance in context refers to one's belief that prospective change entails extrinsic or intrinsic values and benefits (Armenakis and Harris, 2002). It refers to the perceived benefits of particular change that employees appraise for 
themselves (Holt et al., 2007), and there is something of greater value it possesses for them (Armenakis \& Harris, 2009). According to Haffar et al. (2019), employees' extent of participation and willingness to change would be high when perceived promotional opportunities associated with the change are high, that ultimately lead to higher level of change implementation. Taken an account, number of scholars have identified valence as an important facet to influence employees' reactions to change (e.g. Armenakis \& Harris, 2002; Faupel \& Sub, 2018; Haffar et al., 2019; Rafferty \& Minbashian, 2019; Yuan \& Woodman, 2007). For instance, Zimmermann and Fellows (2017) while examining the offshore impact of change in a sample of UK firms (offshored their business across countries) observed that the magnitude of employees' commitment to the corresponding change was higher when their level of valence was high. Likewise, Haffar and colleagues (2019) also reported employees with high degree of valence found more associated with the total quality management practices.

With regards to the role of personal valence as a mediator, social exchange theory adequately explains this mechanism, wherein employee's high expectations about the targeted object, shaped by his or her perception regarding the extent of social support they have been receiving from top management which leads to one's greater productivity and performance (Lee, 2018). In a recent study, Faupel and Sub (2018) also noted valence as an effective motivational mechanism to spur change support behavior among employees. Although, personal valence has found to be a strong determinant in variety of contexts such as organizational studies (Tannenbaum, Mathieu, Salas, \& Cannon-Bowers, 1991), education (Zimmerman, Bandura, \& Martinez-Pons, 1992), and public organizations (Lee, 2018). However, this study strives to examine the mediating role of change-valence and its mechanism to effectively transform one's attribution regarding the management support towards change into change supportive behaviors particularly in university context. We argue that one's belief that top administration is serious and concerned about the change; encourage and support them during all stages of change implementation; and they will receive valuable economic inducements in return will likely to increase the degree of their support towards change. In other words, perceived management support likely to enhance one's positive expectations that corresponding change will benefit them in the long run once being executed. Thus, we hypothesize that change-valence positively mediates the relationship between perceived management support and dimensions of behavioral support for change.

H2a: Change valance mediates the positive relationship between perceived management support and compliance behavior

$\mathrm{H} 2 \mathrm{~b}$ : Change valance mediates the positive relationship between perceived management support and championing behavior

\section{RESEARCH MODEL}

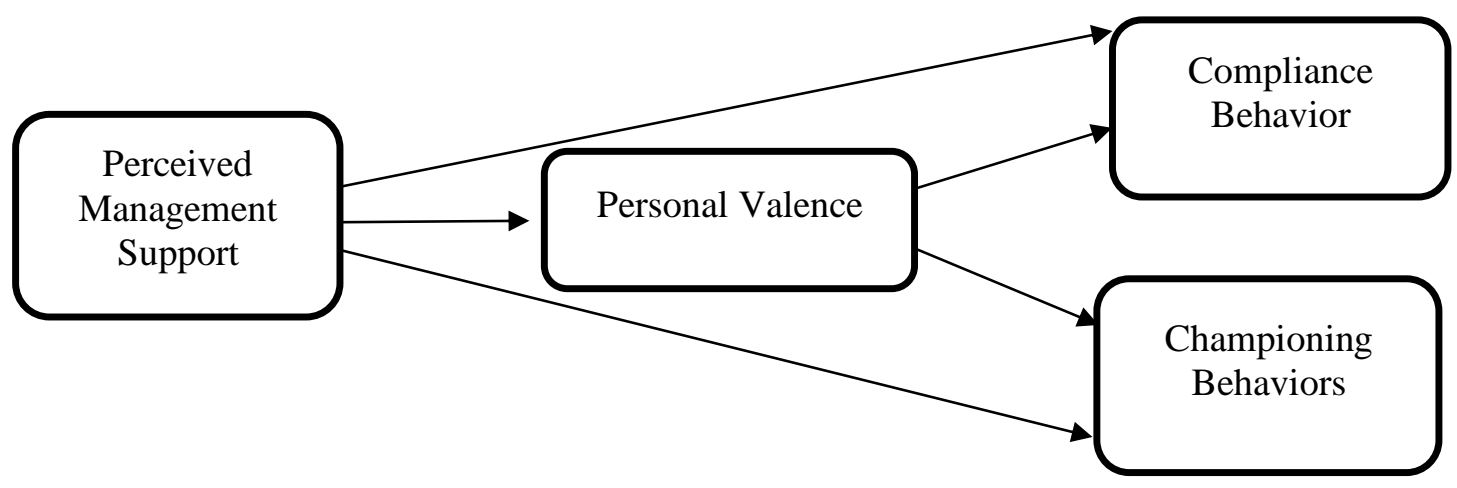




\section{METHODS AND DATA ANALYSIS}

The academic staff of six public sector universities located in two provinces (i.e. Punjab and Sindh) of Pakistan; were the population of this study from whom the data was drawn. The universities have been going through the quality enhancement initiatives undertaken by the higher education commission of Pakistan such as implementation of performance appraisal, tenure track status (TTS), research and promotion policies. The data was randomly drawn from the pooled respondents of selected universities via proportionate stratified random sampling technique. Whereby sampling frame was generated, based on the total number of academic staff in representative university and its relative proportion in the study. Using Krejcie \& Morgan's (1970) sample determination criteria, the study distributed 545 questionnaires to targeted participants and retrieved 308 questionnaires in response, thus accounted for 57\% of the response rate. After screening the data for multivariate outliers, 292 responses found usable for data analysis. The 292 responses consider as sufficient to run data for multivariate analysis and estimations. It is adequately satisfying the minimal responses threshold to carry out statistical analysis as suggested by the past scholars (Hair, Black, Babin \& Anderson, 2019; Kline, 2011). In corresponding responses, male participants constitute $73 \%$ of the sample. The participants with age group 36 to 45 years relatively represents larger proportion of $31 \%$ than rest. Likewise, $24 \%$ of the participants were of having experience ranging from 16 to 20 years. Around $55 \%$ of them were Lecturers and 49\% possesses the Master's degree.

\section{Measures}

Behavioral support for change was measured using 9 items scale comprises of compliance (3) and championing behavior (6) developed by (Herscovitch \& Meyer, 2002). The scale was revised with few amendments wherein 'organization' was replaced with 'university' while 'change' was labelled as quality enhancement initiative by the university'. Sample item includes, "I speak positively about the quality enhancement initiative introduced by the university to colleagues". On the other hand, perceived management support was measured using a six items scale conceptualized by (Holt et al., 2007). Sample item includes "Our senior leaders have encouraged all of us to embrace the quality enhancement initiative introduced by the university".

Personal valance was measured using a three items scale conceptualized by (Holt et al., 2007). Sample item includes "My future in this job will be limited because of this quality enhancement initiative introduced by the University." (Reverse Item). All four constructs were measured on a five point likert scale ranged from $1=$ Strongly disagree to $5=$ Strongly agree.

\section{RESULTS}

Table 1 illustrates the summary of descriptive statistics including zero-order correlation and reliability analysis of the working constructs. The mean values of all factors found above their relative midpoint ranging from $M=3.29$ to $M=3.60$, thus indicated that the academic staff were generally in agreed with the statements inquired during the data collection. Moreover, the reliability analysis, that has been assessed using Cronbach's alpha values also fall above the threshold level of 0.70 (as suggested by (Nunnally, 1978) ranging from 0.80 to 0.83 thereby showing the scales used to measure the constructs are reliable. In addition, all inter-construct correlations were found significant and pointed in the hypothesized direction.

Table 1: Descriptive and Reliability Statistics

\begin{tabular}{l|llllll}
\hline \multicolumn{2}{l}{} & Mean & SD & $\mathbf{1}$ & $\mathbf{2}$ & $\mathbf{3}$ \\
\hline 1 & PMS & 3.41 & 0.73 & $(0.81)$ & & \\
2 & PV & 3.29 & 0.98 & $0.25^{*}(0.80)$ & & \\
3 & COMP & 3.60 & 1.02 & $0.36^{*}$ & $0.36^{*}(0.82)$ & \\
4 & CHAMP & 3.39 & 0.80 & $0.37^{*}$ & $0.31^{*}$ & $0.37^{*}(0.83)$ \\
\hline
\end{tabular}


$* \mathrm{P}<0.05$

Values in parenthesis are Cronbach's alpha for reliability assessment

PMS: Perceived Management Support, PV: Personal Valence, COMP: Compliance

Behavior, CHAMP: Championing Behavior

Table 2: Path Analysis between the Working Constructs

\begin{tabular}{lllrrrr}
\hline & & & Estimate & S.E. & C.R. & P \\
\hline PV & $<---$ & PMS & .343 & .077 & 4.444 & $* * *$ \\
COMP & $<---$ & PMS & .406 & .075 & 5.383 & $* * *$ \\
CHAMP & $<---$ & PMS & .332 & .060 & 5.572 & $* * *$ \\
COMP & $<---$ & PV & .297 & .056 & 5.350 & $* * *$ \\
CHAMP & $<---$ & PV & .191 & .044 & 4.353 & $* * *$ \\
\hline$* * * \mathrm{P}<.001$ & & & & & &
\end{tabular}

Path analysis was used to test our hypotheses H1a, H1b. The hypotheses H1a and H1b concern with the positive effect of perceived management support on dimensions of behavioral support for change such as compliance and championing behavior. The result indicated that perceived management support has a significant impact on both compliance (COMP <--- PMS: $\beta=0.343$; $S E=0.077 ; p<.01$ ) as well as championing behavior (CHAMP <--- PMS: $\beta=0.332 ; S E=$ $0.060 ; p<.01)$ as shown in Table 3 and Figure 1. Thereby the result provided support for the corresponding hypothetical association.

Figure 1: Path Analysis

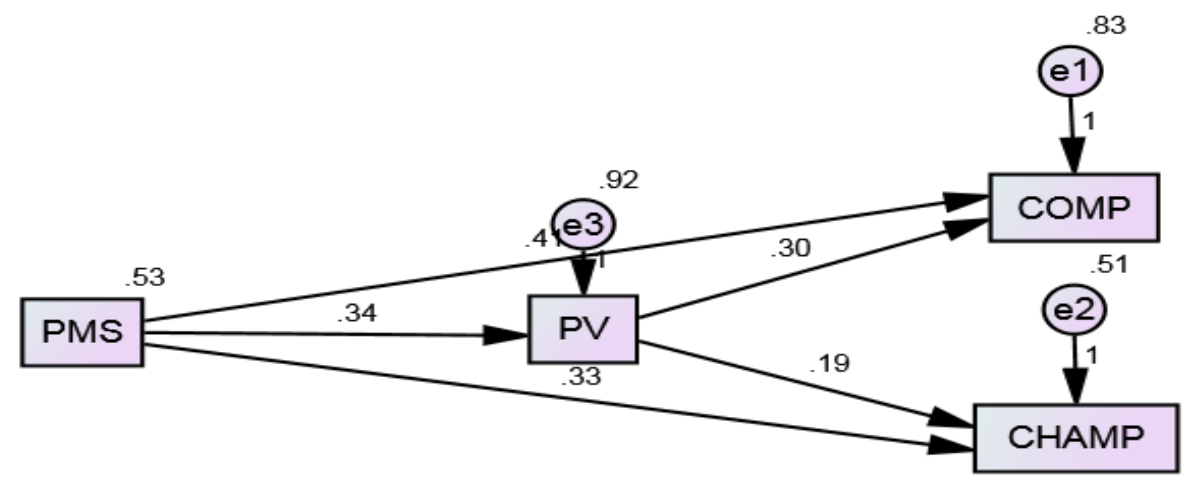

Moreover, the $\mathrm{H} 2 \mathrm{a}$ and $\mathrm{H} 2 \mathrm{~b}$ were poised to examine the mediating role of change-efficacy in translating the impact of perceived management support to the dimensions of behavioral support for change. As predicted, the result showed that the impact of perceived management support on compliance (COMP <--- CEF <--- PMS: $\beta=0.10 ; S E=0.03 ; L L C I=0.05 ; U L C I=0.18$ ) and championing behavior (CHAMP <--- CEF <--- PMS: $\beta=0.07 ; S E=0.02 ; L L C I=0.03$; $U L C I=0.12)$ have indirectly been influenced by the presence of change-efficacy. Thus, providing support to both of our hypotheses (see Table 4) 
Table 3: Mediation Analysis

\begin{tabular}{|c|c|c|c|c|}
\hline & \multicolumn{4}{|c|}{ Compliance } \\
\hline & \multirow[b]{2}{*}{ Estimates } & \multirow[b]{2}{*}{ SE } & \multicolumn{2}{|c|}{ BC $95 \%$ CI } \\
\hline & & & Lower & Upper \\
\hline Total effect of PMS on COMP & 0.51 & 0.08 & 0.35 & 0.66 \\
\hline Direct Effect of PMS on COMP & 0.41 & 0.06 & 0.25 & 0.55 \\
\hline \multirow[t]{2}{*}{ Indirect Effect of PMS on COMP via PV } & 0.10 & 0.03 & 0.05 & 0.18 \\
\hline & & \multicolumn{3}{|c|}{ Championing } \\
\hline Total effect of PMS on CHAMP & 0.40 & 0.07 & 0.28 & 0.51 \\
\hline Direct Effect of PMS on CHAMP & 0.33 & 0.06 & 0.21 & 0.45 \\
\hline Indirect Effect of PMS on CHAMP via PV & 0.07 & 0.02 & 0.03 & 0.12 \\
\hline
\end{tabular}

\section{DISCUSSION}

The key objective of this study was to examine perceived management support during the time of organizational change to bring about one's behavioral support for change. It also aimed to identify the potential mechanism through which this association effectively transformed into behavioral support for change. The proposed framework was established and applied by using the social exchange theory (SET) to explain the phenomenon under observation. The finding provided support to our hypotheses H1a and H1b associated with direct link of perceived management support and behavioral support for change. The results found parallel to the past studies whereby perceived management support found positively related to one's change oriented outcomes (i.e. (Bakari et al., 2017; Haffar et al., 2019; Rafferty \& Minbashian, 2019).

Furthermore, the mediation results also confirmed the role of valence as potential mechanism to facilitate the change supportive behaviors both at passive (compliance) and active (championing) level. Thereby the findings support the prior research wherein change-valence has been demonstrated as potential mediator in stimulating positive work behaviors (Lee, 2018; Faupel \& Sub, 2018). Moreover, the findings also found in line with the studies pointing valence as an important attribute in determining the change-related support outcomes (e.g. Armenakis \& Harris, 2002; Haffar et al., 2019; Rafferty \& Minbashian, 2019; Yuan \& Woodman, 2007; Zimermann et al., 2017). In addition, it is also found consistent with the assumptions of social exchange theory, which suggests when individuals perceive that the target in hand is beneficial; receiving adequate support from top management; more likely it may unleash the motivational stimulus among them to get along with the goals under considerations. The study hence effectively synchronized the subsequent notion empirically and validate its underpinning to the context of the study's research setting.

In brief, the study has established the role of perceived management support as a context factor and a resource to stimulate change supportive behaviors. It also provides support for personal valance as a person factor to lead the change processes. The study thereby confirms that both context and person factors are empirically a valid choice to incorporate to develop an effective support for change mechanism as suggested by scholars (i.e. Fugate \& Soenen, 2018; Oreg et al., 2011; Rafferty et al., 2013). The study thereby contributes to the literature on organizational change by two ways. First, it has responded to the call by past researchers (Fugate \& Soenen, 2018; Oreg et al., 2011; Rafferty et al., 2013) to examine both person and context factors to unveil the likely circumstances that promote or inhibit the change supportive orientation by the individuals. The study in response, examined both aspects and provide empirical support to the subsequent call. Second, though past studies have demonstrated the impact of perceived management support and personal valence on one's commitment and support to change (Bakari et al., 2017; Rafferty \& Minbashian, 2019), however, examining personal valence as an intervening mechanism align with social exchange theory, particularly the active-passive behavioral activation (i.e. compliance and championing) towards change has literally been 
overlooked. Hence, this study shed lights on this view and empirically drawn support in this regard.

In brief, the present study adds to the scarce literature on organizational change by focusing on the behavioral support for change and by identifying change-valence as an explanatory underlying variable. In doing so, the study helps to clarify how one's perceived management support influence individuals during change. The consideration of valence as a mediator in the present study expands our knowledge and understanding about the meaning of attractive consequences of change if individuals found positive at it. It has been suggested in prior literature that valence can be a more proximal antecedent of individual's reactions to change than other antecedents are (Oreg et al., 2011), an idea that is empirically supported in the present study. In line with previous research, the study finds that the perception of positive outcomes of change is one of the most important factors in motivating individuals, academic staff in particular to support a change.

Moreover, the findings also revealed that academic staff was more involved in compliance oriented behavior which is categorized as passive mode of support behavior than championing behavior that has been tagged as active form of behavior (see Kim, Hornung, \& Rousseau, 2011). The hypothetical associations even found stronger in relation to compliance behavior than championing behavior. It suggests that the academic staff is more prone to comply to the subsequent change initiatives at the minimum acceptable level than act as champions to advocate change. The study therefore unfolds that employees' desirable response to change initiative could be promoted if the extent of support from top management and their level of valence regarding change increases. Conclusively the study provides scholars and practitioners a theoretical and empirical rationale for the underlying relationships and mechanism to develop the support for change particularly under the university settings.

\section{LIMITATIONS AND FUTURE DIRECTIONS}

Despite of the empirical contributions of the study, the findings of the study should be understood with certain limitations. First the findings are based on the cross-sectional research design and single source data that restrain our claim of causal relationship reported in this study. Although the framework was developed with extant literature review anchored with theoretical underpinning and results also provided support and confirmation of the propositions, however, more research has been needed particularly via longitudinal or dyadic design to validate the study findings. Second, the findings of the study are only subject to the academic staff of public sector universities. Therefore, further research is needed across cultures, sectors and functional areas to confirm the generalizability of the model.

\section{REFERENCES}

Armenakis, A. A., \& Harris, S. G. (2002). Crafting a change message to create transformational readiness. Journal of organizational change management.

Armenakis, A. A., Bernerth, J. B., Pitts, J. P., \& Walker, H. J. (2007). Organizational change recipients' beliefs scale: Development of an assessment instrument. The Journal of Applied Behavioral Science, 43(4), 481-505.

Bakari, H., Hunjra, A. I., \& Niazi, G. S. K. (2017). How does authentic leadership influence planned organizational change? The role of employees' perceptions: Integration of theory of planned behavior and Lewin's three step model. Journal of Change Management, 17(2), 155187.

Bouckenooghe, D., M. Schwarz, G., \& Minbashian, A. (2015). Herscovitch and Meyer's threecomponent model of commitment to change: Meta-analytic findings. European Journal of Work and Organizational Psychology, 24(4), 578-595. 
Cinite, I., Duxbury, L. E., \& Higgins, C. (2009). Measurement of perceived organizational readiness for change in the public sector. British Journal of Management, 20(2), 265-277.

Cascio, W. F., \& Aguinis, H. (2008). Research in industrial and organizational psychology from 1963 to 2007: Changes, choices, and trends. Journal of Applied Psychology, 93(5), 1062.

Coyle-Shapiro, J. A. M. (1999). Employee participation and assessment of an organizational change intervention: A three-wave study of total quality management. The Journal of Applied Behavioral Science, 35(4), 439-456.

Day, K. M., Armenakis, A. A., Feild, H. S., \& Norris, D. R. (2012). Other organizations are doing it, why shouldn't we? A look at downsizing and organizational identity through an institutional theory lens. Journal of Change Management, 12(2), 165-188.

Falbe, C. M., \& Yukl, G. (1992). Consequences for managers of using single influence tactics and combinations of tactics. Academy of Management Journal, 35(3), 638-652.

Faupel, S., \& Süß, S. (2019). The effect of transformational leadership on employees during organizational change-an empirical analysis. Journal of Change Management, 19(3), 145-166.

Fugate, M., \& Soenen, G. (2018). Predictors and processes related to employees' change-related compliance and championing. Personnel Psychology, 71(1), 109-132.

Haffar, M., Al-Karaghouli, W., Irani, Z., Djebarni, R., \& Gbadamosi, G. (2019). The influence of individual readiness for change dimensions on quality management implementation in Algerian manufacturing organisations. International Journal of Production Economics, 207, 247-260.

Hair, J. F., Black, W. C., Babin, B. J., Anderson, R. E., \& Tatham, R. L. (1998). Multivariate data analysis (Vol. 5). Prentice hall Upper Saddle River, NJ.

Herscovitch, L., \& Meyer, J. P. (2002). Commitment to organizational change: Extension of a three-component model. Journal of Applied Psychology, 87(3), 474.

Holt, D. T., Armenakis, A. A., Feild, H. S., \& Harris, S. G. (2007). Readiness for organizational change: The systematic development of a scale. The Journal of Applied Behavioral Science, $43(2), 232-255$.

Kavanagh, M. H., \& Ashkanasy, N. M. (2006). The impact of leadership and change management strategy on organizational culture and individual acceptance of change during a merger. British Journal of Management, 17(S1), S81-S103.

Kim, T. G., Hornung, S., \& Rousseau, D. M. (2011). Change-supportive employee behavior: Antecedents and the moderating role of time. Journal of Management, 37(6), 1664-1693.

Krejcie, R. V., \& Morgan, D. W. (1970). Determining sample size for research activities. Educational and Psychological Measurement, 30(3), 607-610.

Iqbal, A., \& Asrar-ul-Haq, M. (2018). Establishing relationship between TQM practices and employee performance: The mediating role of change readiness. International Journal of Production Economics, 203, 62-68.

Oreg, S., Bartunek, J. M., Lee, G., \& Do, B. (2018). An affect-based model of recipients' responses to organizational change events. Academy of Management Review, 43(1), 65-86.

Oreg, S., Vakola, M., \& Armenakis, A. (2011). Change recipients' reactions to organizational change: A 60-year review of quantitative studies. The Journal of Applied Behavioral Science, $47(4), 461-524$. 
Neves, P. (2009). Readiness for change: Contributions for employee's level of individual change and turnover intentions. Journal of Change Management, 9(2), 215-231.

Rafferty, A. E., Jimmieson, N. L., \& Armenakis, A. A. (2013). Change readiness: A multilevel review. Journal of Management, 39(1), 110-135.

Rafferty, A. E., \& Minbashian, A. (2019). Cognitive beliefs and positive emotions about change: Relationships with employee change readiness and change-supportive behaviors. Human Relations, 72(10), 1623-1650.

Tomprou, M., Nikolaou, I., \& Vakola, M. (2012). Experiencing organizational change in Greece: The framework of psychological contract. The International Journal of Human Resource Management, 23(2), 385-405.

Schreyögg, G., \& Sydow, J. (2010). Crossroads—Organizing for fluidity? Dilemmas of new organizational forms. Organization Science, 21(6), 1251-1262.

Vakola, M. (2014). What's in there for me? Individual readiness to change and the perceived impact of organizational change.

Wanberg, C. R., \& Banas, J. T. (2000). Predictors and outcomes of openness to changes in a reorganizing workplace. Journal of applied psychology, 85(1), 132. 